\title{
La autonomía de la voluntad como principio previo a la autoconfiguración de las cláusulas del contrato
}

The autonomy of the will as a principle prior to the self-configuration of the clauses of the contract

A autonomia da vontade como princípio anterior à autoconfiguração das cláusulas do contrato

L'autonomie de la volonté comme principe préalable à l'autoconfiguration des clauses du contrat

\section{\begin{tabular}{l|l} 
Idarmis Knight Soto & ${ }^{1}$ \\
Universidad Ciego de Ávila
\end{tabular} Marla Iris Delgado Knight ${ }^{2}$ Máximo Gómez Báez, Cuba}

Revista Derechos en Acción / ISSN 2525-1678 / e-ISSN 2525-1686

Año 4/N 10 verano 2018/2019 (21 diciembre a 21 marzo), 204-216 DOI: https://doi.org/10.24215/25251678e250

ORCID: https://orcid.org/0000-0003-4713-7488 y 0000-0003-1206-2092

Recibido: $17 / 11 / 2018$

Aprobado: 12/03/2019

Resumen: La autoconfiguración de las cláusulas del contrato sobreviene en obligaciones entre las partes y, de conformidad con la autonomía de la voluntad, responden al interés general, como principio previo al ordenamiento jurídico. La sistematización de su fundamento jurídico permite -mediante un análisis lógico- la concreción de conocimientos sobre la estructura teórica del contrato como instrumento jurídico regulador de la economía. Dicho análisis se basa en la buena fe que irrumpe como un principio general del Derecho, que construye actuaciones condicionadas y derivan consecuencias jurídicas a interpretarse de la forma que más

\footnotetext{
1 Doctora en Ciencias Jurídicas. Profesora Titular Universidad Ciego de Ávila Máximo Gómez Báez. Consultora Jurídica.

2 Especialista en Derecho Civil Patrimonial de Familia. Profesora Asistente. Universidad Ciego de Ávila Máximo Gómez Báez. Notaria
} 
favorezca su aplicación. Esa interpretación es la vía para alcanzar la progresividad de los derechos del individuo en la sociedad a partir del desarrollo de las políticas públicas.

Palabras claves: autonomía de la voluntad. contratos. buena fe.

Abstract: The autoconfiguration of the clauses of the contract ensues in obligations between the parties and in accordance with the autonomy of the will respond to the general interest, as a prior principle to the legal system, the systematization of its legal basis allows through a logical analysis the concretion of knowledge about the theoretical structure of the contract as a regulatory legal instrument of the economy, based on good faith that breaks down as a general principle of law, which constructs conditioned actions and derives legal consequences to be interpreted in the way that favors its application, as a way to achieve the progressiveness of the rights of the individual in society based on the development of public policies.

Keywords: autonomy of the will, contracts, good faith.

Resumo: A autoconfiguração das cláusulas do contrato sobrevem em obrigações entre as partes e de acordo com a autonomia da vontade respondem ao interesse geral, como princípio prévio ao sistema jurídico, a sistematização da sua base jurídica permite através de uma análise lógica a concreção do conhecimento sobre a estrutura teórica do contrato como instrumento jurídico regulador da economia, baseado na boa-fé que se decompõe como um princípio geral do direito, que constrói ações condicionadas e derivam consequências jurídicas a interpretar-se da maneira que mais favoreceu a sua aplicação, como forma de alcançar a progressividade dos direitos do indivíduo na sociedade a partir do desenvolvimento de políticas públicas.

Palavras-chave: Autonomia da vontade. Contratos. Boa-fé.

Résumé: L'autoconfiguration des clauses du contrat se termine par des obligations entre les parties conformément à l'autonomie du testament, en réponse à l'intérêt général en tant que principe prioritaire de l'ordre juridique. La systématisation de sa base juridique permet, à travers une analyse logique, de concrétiser des connaissances sur la structure théorique du contrat en tant qu'instrument juridique réglementaire de l'économie. Cette analyse est fondée sur la bonne foi, qui est érigée 
en principe général du droit et construit une action conditionnée et des conséquences juridiques à interpréter de la manière qui favorise le mieux son application. Cette interprétation est le moyen de parvenir à la progressivité des droits de l'individu dans la société sur la base de l'élaboration de politiques publiques.

Mot-clés: Autonomie de la volonté. Des contrats. De bonne foi.

\section{Exordio}

El contrato como acto jurídico es aquel mediante el cual se crean, modifican y extinguen relaciones jurídicos- económicas de naturaleza obligatoria, para la ejecución de una actividad productiva, comercial o de prestación de servicios, en el que intervienen tanto personas naturales y jurídicas nacionales ${ }^{3}$ como personas naturales y jurídicas extranjeras que estén domiciliadas establecidas o autorizadas para operar en el país ${ }^{4}$. Constituye una institución reguladora, al que la ley le otorga poder en la concertación, interpretación y ejecución, no solo a las partes contratantes sino también cuando se adquiere relación con terceros.

Con fundamento en lo antes expuesto este artículo tiene como objetivo un somero estudio teórico sobre los principios que rigen las relaciones contractuales y así la igualdad como principio informante entre las partes conlleva a una forma de comportamiento que no distorsiona las cláusulas convenidas en el contrato, y su razón jurídica impone límites al desequilibrio contractual, que en principio se hace previsible en determinadas circunstancias, su fuerza vinculante permite la intangibilidad ${ }^{5}$, de ahí su obligatoriedad una vez celebrado.

\footnotetext{
3 Vid. artículo 39.1 de la Ley 59 “Código Civil Cubano", de fecha 16 de julio de 1987

4 Víd. artículo 1 del Decreto Ley 304, publicado en la Gaceta Oficial de la República de Cuba Ordinaria en fecha 27 de diciembre del 2012

5 Ninguna de las partes puede unilateralmente modificar o extinguir el contrato (...). La sentencia no. 154, de la Sala Económica del Tribunal Supremo de la República de Cuba,
} 


\section{La autorregulación de las relaciones contractuales. Generalidades}

En la génesis de una relación contractual con la declaración de voluntad, sin reserva, se reconoce el objeto y la causa de la obligación, este perfil vinculante es a través de la aceptación expresa de la oferta, que puede llegar al oferente por cualquier medio de comunicación, o en su defecto de forma tácita mediante cualquier acto que indique su conformidad, para esta última condición el silencio o la inacción, por sí solos no constituyen aceptación, es inaplicable la cláusula contractual que sea contraria a una norma imperativa y no pueden ser modificadas por la voluntad de las partes.

La oferta prescribe a los veinte días, de no estar el plazo previamente determinado, de esta forma la validez es un argumento de hecho valorativo con criterio de pertenencia ya sea de adecuación o incompatibilidad al mandato de la norma, se trata de buscar la eficacia del acto como eslabón en el tráfico mercantil.

Ahora bien, la oferta puede realizarse a través de condiciones generales las cuales constituyen cláusulas preparadas redactadas por una de las partes y presentada a la otra mediante proformas, las cuales son negociables y las modificaciones esenciales que se produzcan constituyen una contraoferta que acaece en una nueva oferta, y para que tenga sentido las cláusulas con una agudeza inmediata deben manifestarse de forma contigua de manera tal que pueda cristalizar el contrato.

A contrario sensus, los contratos de adhesión constituyen una forma de obligarse la persona natural o jurídica para

\footnotetext{
dictada en fecha 24 de diciembre de 2012, aduce sobre la contradicción subsistente sobre extremos fundamentales, no dilucidados, que, trascendiendo a lo resuelto, por la iniquidad del proceso, provoca la nulidad de las actuaciones y su retroacción, para que, en ejercicio de la facultad saneadora del tribunal, se subsane la omisión padecida que impidió la resolución efectiva del fondo del asunto. Víd. Art. 7 Decreto Ley 304/12. Para abundar en el tema Cfr. ALBALADEJO GARCIA, M.(1994), Derecho Civil, La obligación y el contrato en general, V.1, Novena Ed. Bosch, Barcelona. pp. 444-448
} 
recibir la prestación de los servicios públicos que se le oferta, fue denominado de esta forma en la doctrina por SALEILLES ${ }^{6}$, constituye una materialización de la voluntad del oferente a través de la aceptación de sus cláusulas mediante documentos preestablecidos, una vez puesto en conocimiento de los adherentes. Resulta interesante aclarar que esas cláusulas no pueden transformarse en abusivas y aunque su interpretación en ocasiones puede resultar oscura (Interpretatio contra proferentem) se admite reclamaciones de carácter formal y previo que impida el perjuicio de los adherentes.

En este sentido coincidimos en que los derechos subjetivos de obligación aparece ante distintas situaciones: a) conducta propia, jurídicamente autorizada y protegida, que viene determinada por el deber que los demás tienen de no realizar ningún acto que pueda perturbarla o hacerla imposible; b) facultad de exigir una conducta de otro; c) poder jurídico de creación, modificación o extinción de las relaciones jurídicas ${ }^{7}$. Por ello, los beneficios del fin práctico de la estandarización de los contratos de adhesión deben gozar de una sólida base jurídica que les permita a los adherentes interpretar las obligaciones como norma de deber jurídico, liberadas de tensiones que articulen posible abuso de derecho, evitando la preeminencia de algunas de las partes.

Otras modalidades reconocidas en materia contractual en la legislación patria son las bases permanentes de contratación y contratos marcos los cuales se encadenan con sucesivos contratos que se otorguen entre ellos, las primeras constituyen indicaciones o líneas generales que se toman en cuenta para la contratación y los segundos constituyen contratos cuyas cláusulas, ya definidas, exigen precisiones que se concretarán en el futuro.

6 Cfr. DIEZ-PICAZO, L. (1996), Fundamentos del Derecho Civil Patrimonial. Introducción teoría del contrato, Vol. I, 5ta edición, Editorial Civitas Madrid, p.347

7 Cfr. RECASENS,L.(1986), Tratado General de Filosofía del Derecho, 3ªed.,Ed.Porrúa, México, pp.232-233 
Si bien los tratos preliminares se instituyen mediante negociaciones dirigidas a la concertación de un contrato, la responsabilidad precontractual no debe objetarse, toda vez que obliga a la reparación inicial, por causales diversas que socavan la buena fe y consiguientemente provoca su ruptura salvo causas justificadas de desistimiento. La propensión negativa o positiva que se asuma responde a la pretensión unilateral de las partes.

El contrato como documento público reivindica su eficacia desde su esencia jurídica que muestra su valor constitutivo con fuerza obligatoria para las partes, sin embargo el contrato verbal aparece reconocido en la legislación cubana ${ }^{8}$, y resulta interesante acotar que las prestaciones sucesivas que se realicen se concretaran mediante un contrato escrito, el cual constituye un nuevo contrato aunque el objeto de la prestación sea idéntico.

\section{II.1. La coherencia jurídica y la integración como principios en el contenido general del contrato}

La relación jurídica entre las partes de un contrato constituyen la manifestación de voluntad de ambas, sus intereses de forma consensuada aparecen ajustados a la realidad práctica del objeto del contrato y de la prestación que derivan, el contenido general de las obligaciones está determinado además por los plazos para su cumplimiento, términos y reglas internacionales, precios y tarifas, condición de pago, los efecto de la falta de pago, parámetros de calidad, plazos de garantía comercial, del seguro, soluciones alternativas para el cumplimiento, exclusividad, aviso, limitación o exención de la responsabilidad, solución de controversias, modificación y terminación del contrato, vigencia del contrato, así como por otros pactos que se quieran incorporar.

La materialización del contenido del contrato constituye el compromiso y reglas de conductas entre las partes, que a nuestro criterio se convierten en obligaciones de deber y poder

8 Como regla general el contrato debe ser escrito, bien sea manuscrito, en forma documental expresa o en sujeción a otro tipo de formalidad. Vid. Artículo 31.1 del Decreto Ley 304/12 
en la relación jurídica y producen efectos en función del interés general con cláusulas de alcance subordinado y social de organización, teniendo en cuenta el sistema de propiedad imperante, la propiedad social.

Por tanto la eficacia del contenido del contrato se encuentra en el cumplimiento de las cláusulas pactadas entre las partes, que no actúan de forma aisladas, sino de forma sistémica con fundamento de validez, logrando la conservación del contrato de manera que la interpretación produzca algún efecto, antes que privar a alguna de ellas, independientemente al cambio de situación patrimonial anterior y posterior al acto.

La coherencia jurídica constituye un corolario de la unidad del contrato y como principio general del Derecho posee valor axiológico que permite orientación ética y tiene sentido dispositivo.

Las fuentes de integración del contrato obligan a distinguir desde soluciones propias, el valor del derecho imperativo, la voluntad de las partes, el derecho dispositivo, hasta los usos y prácticas comerciales generalmente aceptadas, como por ejemplo las reglas de UNIDROIT ${ }^{9}$. La Sentencia no. 92 dictada por la Sala Económica del Tribunal Supremo Popular se pronunció en cuanto a la ineficacia de la cláusula compromisoria al arbitraje por constituir el conflicto sobre disolución de empresa mixta una cuestión de orden público sometida al conocimiento de los tribunales de la jurisdicción ordinaria o estatal cubana por imperatividad de la norma ${ }^{10}$.

La exigencia de coherencia jurídica en la relación contractual constituye un componente legitimador del principio de

\footnotetext{
9 Las fuentes de autointegración se encuentran cuando los mecanismos de integración 0 las fuentes de integración se encuentran en el mismo ordenamiento jurídico, en su interior sin tener que salir de él para completarlo. Por el contrario la heterointegración se refiere a la búsqueda de integración fuera del ordenamiento jurídico, acudiendo a fuentes externas como pueden ser las costumbre, jurisprudencia (...), Cfr. Fernández Bulté, J.(2004), Teoría del Derecho, Ed. Félix Varela, La Habana , p.230
}

10 Víd. Sentencia No. 92 de fecha 24 de julio del 2012 
buena fe que impide la presencia de cláusulas abusivas y suscita la debida protección al consumidor, se trata de evitar efectos discordantes entre el objeto y fin del contrato, constituye una unidad interna para evitar antinomias y lagunas en la aplicación de las cláusulas del contrato.

De lo anteriormente expuesto el iter del contenido del contrato es un esquema estructurado con características ordenadora, fuente del nacimiento de la relación jurídica que tiene eficacia modificativa y extintiva en virtud de cambios objetivos o subjetivos, primando la intangibilidad y la autonomía de la voluntad como principios.

La eficacia modificativa del contrato está caracterizada por los acuerdos de las partes, disposición legal o por decisión judicial, sus causas pueden hacerse constar en suplemento el cual forma parte del contrato. No se ha de olvidar que cualquiera de las partes puede trasmitir a un tercero su posición contractual a través de un contrato básico.

La eficacia extintiva del contrato deja sin efecto la relación jurídica contraída entre las partes, se produce por acuerdos adoptados entre ellas, declaración judicial o cualquier otra de las causas reconocidas en las normas jurídicas, la parte causante responde de los daños y perjuicios que pueda causar excepto cuando existan causas que reputen exención de la responsabilidad. La norma es clara al señalar que la resolución unilateral del contrato por incumplimiento esencial posee un arquetipo de incidencia para la otra parte por ejemplo si el incumplimiento recae en algunas de las obligaciones principales y se priva sustancialmente a la parte perjudicada de lo que tenía derecho a esperar en virtud del contrato, o si el incumplimiento le otorga a la parte perjudicada razones objetivas y fundadas para creer que no puede confiar en el cumplimiento futuro de la otra.

De cualquier modo, la resolución resarcitoria produce efectos encausados a la reparación del daño e indemnización de los perjuicios ocasionados, quedando expedita la vía de solución de controversia, sin dejar de advertir que el fenómeno causal no afecta las cláusulas que regulen los derechos y obligaciones de 
las partes, por lo que se retrotrae y se adecua a la satisfacción del interés general.

La eficacia y relatividad del contrato son coherente, la relación jurídica contraída entre las partes preconcebida de una situación jurídica produce consecuencias, pero en modo alguno genera obligaciones para terceros, ni estos tienen derecho a invocarlo para hacer recaer sobre las partes obligaciones que estas no han convenido.

\section{II.2. El valor informante de la hermenéutica contractual}

Las VII Partidas de Alfonso el Sabio exponían que interpretar la ley, conocerla, "no es decorar las letras de ella", es comprender su sentido, captar su espíritu, precisar su fin ${ }^{11}$.

Diez PicAzo ${ }^{12}$ planteó que la tarea interpretativa comprende, de esta suerte, una serie de actividades que no tienen siempre el mismo signo:

1. En primer lugar Ia interpretación exige la determinación del sentido de cada uno de los elementos de supuestos de hecho normativo.

2. El segundo lugar, cuando en el supuesto de hecho normativo aparecen conceptos indeterminados la interpretación exige la atribución a los mismos de una carga de valor.

3. El tercer lugar la interpretación impone la búsqueda de un esclarecimiento de las consecuencias que la norma liga con su supuesto.

4. Por último, cuando la norma establece una consecuencia que no se encuentra absolutamente determinada, la interpretación exige la adopción de una decisión.

La calificación del contrato descansa en su contenido, con independencia de la denominación que las partes asignen y la interpretación de las cláusulas oscuras debe favorecer a la parte

11 Cfr. Fernández Bulté, J.: Teoría del Derecho, op. cit, p. 208

12 Cfr. Diez Picazo, L.(1970), La interpretación, Anuario de Derecho Civil, Madrid, p.711. 
que no la haya propuesto o redactado, de existir dudas sobre circunstancias accidentales y el contrato es gratuito, se interpreta a favor de la menor transmisión de derechos e intereses, si por el contrario es oneroso, debe interpretarse a favor de la mayor reciprocidad de prestaciones.

En el supuesto que exista contradicciones entre las condiciones generales y particulares específicamente previstas para ese contrato, prevalecen estas sobre aquellas, salvo que las primeras resulten más beneficiosas sobre las segundas para la parte que no las propuso o no las redactó.

En tal sentido esta interpretación pro consumatore o contra proferentem es una regla que tutela al consumidor y evita la aplicación de cláusulas abusivas, sin embargo un análisis esquemático de la doctrina puede conllevar a un injusto actuar contractual, el remedio está en la búsqueda de la orientación cuyas consecuencias jurídicas favorezcan al consumidor en plano de igualdad ante la ley como mandato constitucional. Se trata en definitiva de buscar la conservación del contrato, al otorgarle sentido a todas sus cláusulas para que produzcan efectos como cuestión esencial y técnica en la práctica contractual, protegiendo su integridad con justo sentido para encontrar la voluntad de las partes, que de tal suerte no se desnaturalice los derechos subjetivos de obligación con alcance de comportamiento en la sociedad.

La estructura jurídica de las cláusulas de los contratos es heterogénea configurada típicamente por su contenido, la interpretación como principio rector tiene basamento en la preeminencia de la obediencia debida a las normas imperativas, bajo el principio de la declaración de voluntad de las partes para darle eficacia al acto e imponer un significado que esté íntimamente ligada a la responsabilidad. De ahí que la información sustancial que se deriva del contrato debe ser oportuna, transparente, evitando un lenguaje ambiguo.

La mayor virtualidad de la interpretación jurídica es buscar la intención de las partes o de una de ellas para precisar las 
vías que conduzcan a evitar ambigüedades y de esta forma evitar abuso del derecho ya sea por ejercitar un derecho contrario a los fines económicos sociales o para dañar a la otra parte, el Código Civil cubano como norma supletoria a la legislación económica se pronuncia en su artículo 4 de la siguiente forma (...) no es lícito su ejercicio cuando el fin perseguido sea causar daño a otro.

También en el orden doctrinal no debemos olvidar que los actos propios “(...) son aquellos que como expresión de libre y espontánea decisión se realizan con el fin de crear, extinguir o modificar algún derecho, luego entonces la teoría del acto propio tiene como esencia la de que así como nadie puede ser perjudicado por actos ajenos, tampoco ninguna persona puede ir válidamente contra sus propios actos, y ello porque si bien toda persona es libre de realizar o no un acto, al realizarlo y reconocer algún derecho a favor de tercero surge una relación jurídica entre ambos que no puede después ser arbitrariamente destruida por actos posteriores (...)"13.

Este pronunciamiento deriva en el fundamento de la imposibilidad de obtener un resultado contrario a la buena fe, reforzando la conducta axiomática de una de las partes que pretenda alcanzar un resultado a partir de la interpretación que bajo la preminencia de las cláusulas jurídicas del contrato, se llegue al estado jurídico pactado.

\section{Epílogo}

El contrato al que se le debe mucha atención, constituye un instrumento de regulación jurídica de la economía, es una forma de intervención pública bajo el principio de autonomía de la voluntad, mediante el cual las partes adoptan sus obligaciones para cumplirlas como la ley misma, perfeccionado bajo la lupa del principio de la buena fe que previene un comportamiento de lealtad, con objetivo de mira a las arras de sus cláusulas para

\footnotetext{
13 Sentencia N ${ }^{\circ} 534$ de 30 de julio del 2004, de la Sala Civil y Administrativo del Tribunal Supremo Popular
} 
la protección al consumidor evitando la resiliación como ineficacia futura cuando existe el tracto sucesivo.

\section{Bibliografía}

Albaladejo Garcia, M.(1994), Derecho Civil, La obligación y el contrato en general, V.1, Novena Ed. Bosch, Barcelona. 1994

Diez-Picazo, L.(1996), Fundamentos del Derecho Civil Patrimonial. Introducción teoría del contrato, Vol. 1, 5ta edición, Editorial Civitas Madrid.

- (1970), La interpretación, Anuario de Derecho Civil, Madrid.

Fernández Bulté, J.(2004), Teoría del Derecho, Ed. Félix Varela, La Habana.

Gómez, Carlos, J.(1991), Estudio sobre los contratos por adhesión a condiciones generales, s. ed., Bogotá D.E.

Knight Soto, I.(2013), Revista Letras Jurídicas, La prescripción .Efectos y fundamentos doctrinales en el Derecho, Año 14, no.28, Universidad Veracruzana, México.

Larroumet, CH.: "La unificación del derecho de las obligaciones en Europa", Revista de Derecho Privado, nueva época, año V, n. ${ }^{\circ}$ 13-14, París, Universidad Pantheón-Assas (París II), eneroagosto de 2006, 69-80,recuperado en :http://www.juridicas. unam.mx/publica/librev/rev/derpriv/cont/13/dtr/dtr4.pdf

Pérez Gallardo, L. (2008), Código Civil de la República de Cuba. Anotado y Concordado, Ed. La Habana.

ReCasens, L.(1986). Tratado General de Filosofía del Derecho, $3^{\mathrm{a}} \mathrm{ed}$., Ed. Porrúa, México.

\section{Legislación}

Constitución de la República de Cuba, de fecha 24 de febrero de 1976, publicada en la Gaceta Oficial Extraordinaria No.3 de fecha 31 de enero de 2003

Ley 59 Código Civil Cubano, de fecha 16 de julio 1987, Divulgación del MINJUS, La Habana, 1988.

Decreto-Ley No.304/2012 "De la Contratación Económica" del Consejo de Estado de fecha 1 de noviembre del 2012 publicado en 
la Gaceta Oficial de la República de Cuba Ordinaria en fecha 27 de diciembre del 2012

Decreto No. 310/2012 "De los Tipos de Contratos", del Consejo de Ministros de fecha 17 de noviembre del 2012 publicado en la Gaceta Oficial de la República de Cuba Ordinaria en fecha 27 de diciembre del 2012

Principios UNIDROIT sobre los Contratos Comerciales Internacionales 2010, International Institute for the Unification of Private Law, Unidroit, Roma, disponible: [http://www.unidroit.org/ spanish/principles/contracts/principles2010/blackletter2010spanish.pdf.

\section{Jurisprudencia}

Sentencia $N^{\circ} 727$ de 29 de junio del 2001 Tribunal Supremo, Sala de lo Civil y de lo Administrativo

Sentencia $N^{\circ} 534$ de 30 de julio del 2004.Tribunal Supremo. Sala de lo Civil y de lo Administrativo

Sentencia $N^{\circ} 406$ de 15 de junio del 2005. Tribunal Supremo. Sala de lo Civil y de lo Administrativo

Sentencia No.1, de fecha 31 de marzo de 2014 de Sala Económico Tribunal Supremo Popular de la República de Cuba.

Sentencia No. 192, de fecha 14 de octubre de 2013 Sala de lo Económico Tribunal Supremo Popular de la República de Cuba. 